\title{
Cytotoxic and cytostatic side effects of chitosan nanoparticles as a non-viral gene carrier
}

\author{
Gizem Bor $^{\mathrm{a}, 1}$, Jennifer Mytych ${ }^{\mathrm{b}, \mathrm{c}, 1}$, Jacek Zebrowski ${ }^{\mathrm{b}, \mathrm{d}}$, Maciej Wnuk ${ }^{\mathrm{b}, \mathrm{c}}$, \\ Gülşah Şanl1-Mohamed ${ }^{\mathrm{e}, *}$ \\ a Biotechnology and Bioengineering Department, Izmir Institute of Technology, Urla, Izmir 35430, Turkey \\ ${ }^{\mathrm{b}}$ Centre of Applied Biotechnology and Basic Sciences, University of Rzeszow, Werynia 502, 36-100 Kolbuszowa, Poland \\ ${ }^{c}$ Department of Genetics, University of Rzeszow, Rejtana 16C, 35-959 Rzeszow, Poland \\ d Department of Plant Physiology, University of Rzeszow, Werynia 502, 36-100 Kolbuszowa, Poland \\ e Department of Chemistry, Izmir Institute of Technology, Urla, Izmir 35430, Turkey
}

\section{A R T I C L E I N F O}

\section{Article history:}

Received 20 May 2016

Received in revised form 17 September 2016

Accepted 19 September 2016

Available online 19 September 2016

\section{Keywords:}

Gene delivery

Chitosan

Nanoparticles

pDNA

Cytotoxicity

Monocytes

Cancer cells
A B S T R A C T

Although chitosan nanoparticles (CNs) became a promising tool for several biological and medical applications owing to their inherent biocompatibility and biodegradability features, studies regarding their effects on cytotoxic and cytostatic properties still remain insufficient. Therefore, in the present study, we decided to perform comprehensive analysis of the interactions between CNs-pKindling-RedMito (pDNA) and different cell line models derived from blood system and human solid tissues cancers. The resulting CNs-pDNA was investigated in terms of their cellular uptake, transfection efficiency, and physico-chemical, cytotoxic and cytostatic properties. The nanoparticles showed high encapsulation efficiency and physical stability for various formulations even after two days time period. Moreover, high gene expression levels were observed after $96 \mathrm{~h}$ of transfection. CNs-pDNA treatment, despite the absence of oxidative stress induction, caused cell cycle arrest in G0/G1 phase and as a consequence led to premature senescence which turned out to be both p21-dependent and p21-independent. Also, observed DNMT2 upregulation may suggest the activation of different pathways protecting from the results of CNsmediated stress. In conclusion, treatment of different cell lines with CNs-pDNA showed that their biocompatibility was limited and the effects were cell type-dependent.

(c) 2016 Elsevier B.V. All rights reserved.

\section{Introduction}

Gene therapy is one of the most promising strategies for treatment of various diseases such as cancer and inflammatory, neurological, cardiovascular or metabolic disorders (Ibraheem et al., 2014; Ragelle et al., 2014). Simultaneously, the choice of a good transfection agent for delivery of nucleic acids is critical for each gene transfer procedure, however most commercially available transfection agents have still some limitations (PerezMartinez et al., 2011). Recently, in gene delivery, viral vectors have been used due to the high transfection efficiency compared to nonviral gene delivery systems. However, toxicity issues such as immunogenicity and mutagenicity limit the clinical applications of

\footnotetext{
* Corresponding author at: Izmir Institute of Technology, Science Faculty, Department of Chemistry Urla, Izmir, Turkey.

E-mail addresses: gulsahsanli@iyte.edu.tr, gulsahsanli@hotmail.com (G. Şanll-Mohamed).

1 These authors contributed equally to this work.
}

the viral vectors. Taking into account safety considerations, nonviral vectors are thought to be more promising nucleic acid carriers compared to viral vectors (Ishii et al., 2001).

Among various non-viral vectors, chitosan (CS) is one of the most commonly studied polymer since its positive charges under slightly acidic conditions allow its interaction with nucleic acids and thus formation of complexes of nanoparticles (Ragelle et al., 2014). On the other side, it is known that many biological effects caused by nanoparticles depend on their size, shape, used dose, behavior of nanoparticles in enviroment (i.e., whether or not their aggregation occurs) and cell type (i.e., suspended versus adherent cell types or healthy versus cancer cell types) (Fu et al., 2014; Mytych et al., 2015a, 2015b). It has been shown that plasmid DNA loaded chitosan nanoparticles (CNs-pDNA) did not cause any cytotoxicity to macrophages (which differentiate from monocytes) (Chellat et al., 2005). Despite these promising results, potential side effects including cytostatic or cytotoxic effects caused by biodegradable nanomaterials like $\mathrm{CNs}$ or/and type of used expression vector system on different cell types are poorly 
understood. Previously, some researchers have reported that GFP transduction might affect the cytophysiology of the targeted cell. For example, it is widely accepted that tagged chromosome proteins may affect the motion of chromosomes. In general, green fluorescent protein (GFP) is considered nontoxic both in in vitro and in vivo systems. However, there are some reports showing side effects of GFP in in vitro and in vivo studies, but the details of molecular mechanism of these interactions still remain unclear (Agbulut et al., 2006, 2007; Baens et al., 2006; Huang et al., 2000; Liu et al., 1999). Recently, it has been shown that Ku80 attenuates cytotoxicity induced by green fluorescent protein transduction independently of non-homologous end joining (Koike et al., 2013).

Moreover, the application of biodegradable nanomaterials as nucleic acid delivery systems for living organisms including humans raises also other important questions about the impact of CNs on efficiency of pDNA condensation. Matsumoto et al. (2009) showed the differences in the transcriptional activity of pDNAs transfected into cells using either cationic lipids or cationic polymers (Matsumoto et al., 2009).

Therefore, in this study, we aimed to use the ionic gelation method for the encapsulation of pKindling-Red-Mito vector into chitosan nanoparticles and to evaluate their potential as safenanocarriers on different cell line models derived from human solid tissues cancers (HeLa and MDA-MB-231) and monocytes (derived from peripheral blood cancer-THP-1).

\section{Materials and methods}

\subsection{Materials}

Plasmid DNA (pKindling-Red-Mito) encoding red fluorescent protein (KFP) and neomycin resistance gene were purchased from Evrogen JSC, Russia. All other reagents, if not otherwise mentioned, were purchased from Sigma Aldrich, Poland and were of analytical grade.

\subsection{Preparation and characterization of CNs-pDNA}

CNs-pDNA were synthesized following the Calvo's ionic gelation procedure (Calvo et al., 1997) with some modifications. According to this procedure, low molecular weight chitosan (50$190 \mathrm{kDa}$ and the degree of acetylation of 75-85\%) was used with tripolyphosphate (TPP) as a crosslinker. Chitosan stock solution $(0.4 \%)$ was prepared by dissolving the chitosan powder in $1 \%(\mathrm{v} / \mathrm{v})$ acetic acid under magnetic stirring. The solution was filtered through sterile $0.45 \mu \mathrm{m}$ membrane and the $\mathrm{pH}$ was adjusted to 5.5. Nanoparticles were spontaneously obtained upon addition of TPP $(0.1 \%)$ and pDNA in nuclease free water to chitosan solution (chitosan to TPP weight ratio of $4: 1$ ). CNs-pDNA at weight ratios of 500:1, 300:1 and 100:1 were generated at room temperature by adding a constant pDNA concentration of $10 \mu \mathrm{g} / \mathrm{ml}$. After complex formation, CNs-pDNA solution was centrifuged at $13500 \mathrm{rpm}$ for $30 \mathrm{~min}$ and then the pellet was dissolved in $2 \mathrm{~mL}$ of nuclease free water ( $\mathrm{pH}$ 7.4) for further use in the in vitro studies.

CNs-pDNA were characterized using dynamic light scattering (DLS) on a Zetasizer Nano ZS (Malvern Instruments Ltd, UK) for determination of mean particle diameter (Z-Average), polydispersion index (P.I.) and zeta potential values. Each measurement was performed in triplicate at a temperature of $25^{\circ} \mathrm{C}$ with an angle of $173^{\circ}$ in ultrapure water.

For the morphological characterization of particles, atomic force microscopy (AFM) was used. All the AFM samples have been deposited on freshly cleaved muscovite mica, incubated for $10 \mathrm{~min}$, and then rinsed with ultrapure water, gently flushed with a stream of nitrogen for drying. The Height Sensor and Peak Force Error AFM images were analyzed with Nanoscope Analysis software (v. 1.40
Bruker Corporation, Germany). Mean diameter and zeta potential of the nanoparticles were estimated by the software provided by Malvern Instruments Ltd.

\subsection{Evaluation of encapsulation efficiency}

To determine the amount of plasmid DNA encapsulated in the chitosan nanoparticles, the difference between the total amount of pDNA and the amount of non-entrapped pDNA remaining in the supernatant after centrifugation $(13,500 \mathrm{rpm}, 30 \mathrm{~min})$ was calculated. For this purpose, the supernatant was used with the corresponding of blank formulation for the calibration curve. It was spectrophotometrically analyzed at $260 \mathrm{~nm}$ for pDNA concentration by NanoDrop ${ }^{\mathrm{TM}}$ 2000/2000c Spectrophotometers.

Furthermore, the physical stability of CNs-pDNA nanoparticles in physiological environment was also determined by $1 \%$ agarose gel electrophoresis in Tris-borate EDTA buffer ( $4.45 \mathrm{mM}$ Tris-base, $1 \mathrm{mM}$ sodium EDTA, $4.45 \mathrm{mM}$ boric acid) at $120 \mathrm{~V}$ for $30 \mathrm{~min}$. Each formulation was loaded on the gel after it was incubated in DMEM medium at $37^{\circ} \mathrm{C}$ for $24 \mathrm{~h}$ and $48 \mathrm{~h}$.

\subsection{Cell culture}

Human cervical (HeLa; ATCC), breast (MDA-MB-231; ATCC) (seeding density $3 \times 10^{3}$ cells $/ \mathrm{cm}^{2}$ ) and peripheral blood (THP-1; ECACC) (seeding density $2 \times 10^{5}$ cells $/ \mathrm{ml}$ ) cancer cells were cultured in Dulbecco's Modified Eagle's medium (DMEM) (for HeLa and MDA-MB-231) or Roswell Park Memorial Institute medium (RPMI 1640) (for THP-1). They were supplemented with $10 \%$ fetal calf serum (FCS) and an antibiotic and antimycotic mixed solution ( $100 \mathrm{U} / \mathrm{ml}$ penicillin, $0.1 \mathrm{mg} / \mathrm{ml}$ streptomycin and $0.25 \mathrm{mg} /$ $\mathrm{ml}$ amphotericin B) at $37^{\circ} \mathrm{C}$ in a humidified atmosphere in the presence of $5 \% \mathrm{CO}_{2}$ until they reached confluence. Typically, cells were passaged by trypsinization (adherent cells) or direct dilution (suspension cells) to a seeding density.

\subsection{In vitro transfection studies}

Cells were seeded onto 96-well plate at a density of $3 \times 10^{3}$ (HeLa and MDA-MB-231) or $2 \times 10^{4}$ (THP-1) cells per well and treated with CNs-pDNA at different concentrations and weight ratios of 500:1, 300:1 and 100:1. After $24 \mathrm{~h}$ incubation, the medium and complexes were removed, media was replaced with fresh medium additionally containing neomycin sulphate $(1 \mathrm{mg} / \mathrm{ml})$ as selection agent. The live cells were examined after $96 \mathrm{~h}$ with In Cell Analyzer 2000 (GE Healthcare, UK) equipped with a high performance CCD camera. The percentage of transfected cells (\%) were calculated by qualitative analysis of the acquired images. Each transfection experiment was carried out as triplicate. Stable cell lines (stable CNs-pDNA) were obtained by continuous longterm culture in medium supplemented $1 \mathrm{mg} / \mathrm{ml}$ neomycin sulphate.

\subsection{Cell viability and cell cycle analysis}

MTT assay was performed to evaluate the cell viability after $24 \mathrm{~h}$ treatment with different formulation of CNs-pDNA (500:1, 300:1 and 100:1). Briefly; cells were seeded onto 96-well plates at a density of $3 \times 10^{3}$ (HeLa and MDA-MB-231) or $2 \times 10^{4}$ (THP- 1 ) cells per well. After $24 \mathrm{~h}$ treatment, the formulations were discarded and replaced with MTT-containing medium $(500 \mu \mathrm{g} / \mathrm{ml})$. After $4 \mathrm{~h}$ incubation at $37^{\circ} \mathrm{C}$, formazan crystals were dissolved in anhydrous dimethyl sulfoxide (DMSO). Absorbance was read at $570 \mathrm{~nm}$ (measurement wavelength) and at $630 \mathrm{~nm}$ (reference wavelength) by Tecan Infinite ${ }^{\circledR}$ M200 absorbance mode microplate reader. 
Metabolic activity at standard growth conditions was considered as $100 \%$.

The behaviour of cells in a given cell cycle position was quantitated by ImageJ $1.37 \mathrm{v}$ software (http://rsb.info.nih.gov/ij/ index.html) with DAPI as staining marker of the cell nuclei, after $72 \mathrm{~h}$ treatment with CNs-pDNA.

\subsection{Senescence-associated $\beta$-galactosidase activity (SA- $\beta$-gal)}

Cells were seeded onto 6-well plates at the density $10^{4}$ (HeLa or MDA-MB-231) or $6 \times 10^{5}$ (THP-1) cells/well and after $72 \mathrm{~h}$ treatment with CNs-pDNA, they were fixed by fixation solution containing $2 \%$ formaldehyde, $0.2 \%$ glutaraldehyde for $5 \mathrm{~min}$, room temperature (RT). Then, cells were washed two times with PBS and staining solution was added $(5 \mathrm{mM}$ potassium ferrocyanide, $5 \mathrm{mM}$ potassium ferricyanide, $150 \mathrm{mM} \mathrm{NaCl}, 2 \mathrm{mM} \mathrm{MgCl}, 1 \mathrm{mg} / \mathrm{ml} 5$ bromo-4-chloro-3-inolyl- $\beta$-D-galactoside (X-gal), $40 \mathrm{mM}$ citric acid/sodium phosphate, $\mathrm{pH}$ 6.0). After overnight incubation in $37^{\circ} \mathrm{C}$, cells were washed with PBS and photographed with an Olympus BX71 light inverted microscope equipped with a DP72 CCD camera and a computer image analysis system Cell^ ${ }^{\wedge}$. SA$\beta$-gal-positive cells were scored per 100 total cells analyzed [\%].

\subsection{Oxidative stress}

Cells were seeded at a density of $3 \times 10^{3}$ cells $/ \mathrm{cm}^{2}$ (HeLa and MDA-MB-231) or $2 \times 10^{5}$ cells/ml (THP-1) and treated with CNspDNA for $72 \mathrm{~h}$ (Rossert et al., 2014). Then, cells were washed and suspended in PBS containing 0.1\% glucose, $0.5 \mathrm{mM}$ EDTA and $5 \mu \mathrm{M}$ $2^{\prime}, 7^{\prime}$-dichlorodihydrofluorescein diacetate $\left(\mathrm{H}_{2}\right.$ DCF-DA) (Sudheesh Kumar et al., 2013). Fluorescence light was monitored in a Tecan Infinite ${ }^{\circledR}$ M200 absorbance mode microplate reader at $495 \mathrm{~nm}$ (measurement wavelength) and at $525 \mathrm{~nm}$ (reference wavelength) (Mytych et al., 2014, 2015b).

\subsection{Western blotting}

Whole cell protein extracts were prepared according to Mytych et al. (Mytych et al., 2014). Proteins were detected using primary antibodies anti-p21 (1:100) (Abcam), anti-DNMT2 (1:500) or anti$\beta$-actin (1:10000) (Thermo Scientific) and a secondary antibody conjugated to Horseradish Peroxidase (HRP) (1:80000). The protein bands visualization was conducted using the Pierce ${ }^{\mathrm{TM}}$ ECL Western Blotting Substrate (Life Technologies) and a G:BOX imaging system.

\subsection{Statistical analysis}

Data were presented as mean \pm standard deviation from at least three independent experiments. Statistical significance was assessed by One-way ANOVA using GraphPad Prism 5, and with the Dunnett's multiple comparison tests.

\section{Results and discussion}

\subsection{Formation and characterization of CNs-pDNA}

In the present study, the preparation of the chitosan nanoparticles was based on ionic gelation interactions between the positively charged polymer and negatively charged TPP. According to our initial studies, the optimized nanoparticle formation was achieved with $5 \mathrm{mg} / \mathrm{ml}$ chitosan concentration and 4:1 CS:TPP mass ratio. The obtained CNPs were spherical or ellipsoidal shape having the size of $91.7 \pm 0.6 \mathrm{~nm}$ and the PDI of 0.214 supported by DLS measurements. The formation of CNs with pDNA was formulated using different CNs amount with fixed pDNA concentration $(10 \mu \mathrm{g} / \mathrm{ml})$ and the formulated compounds were characterized by physically and chemically in details. As shown in Table 1 , the ratio of mixing solution of CS and pDNA affect the particle size, clearly. The size of nanoparticle formation was CS amountdependent, size was increased with higher CS in the formulation as reported by others (Gan et al., 2005; Omar Zaki et al., 2015). The five times increased CS amount resulted in nearly 1.5 times bigger size nanoparticle formation.

The PDI value of chitosan nanoparticles was 0.214 while that of pDNA loaded chitosan nanoparticles was 0.581 for the formulation of 500:1 (CS:pDNA), thus indicating an acceptable particle size distribution (PDI $<0.6$ ) (Table 1 ). A small reduction was observed in zeta potential according to increasing amount of the pDNA loading. As it was discussed previously, this could be explained by the presence of some negatively charged pDNA on the surface of the nanoparticles (Csaba et al., 2009). The methodology employed here resulted in high encapsulation efficiency of pDNA crosslinked chitosan nanoparticles. The increasing amount of chitosan showed a high efficiency for the encapsulation of pDNA, reaching almost 99\% for the formulation with the highest theoretical DNA loading (Table 1).

The shape of the CNs-pDNA was determined by atomic force microscope (AFM). All the formulated compounds with different pDNA loading have displayed similar well defined spherical shape particles and some unwanted aggregates (Fig. 1). The heterogeneous morphology having suffered aggregates obtained in this study agrees with previously reported studies (Erbacher et al., 1998a; Köping-Höggård et al., 2003). The measured size of CNspDNA by AFM was almost same as obtained by DLS.

Gel electrophoresis studies were performed to assess the association of pDNA within nanoparticles after incubated in DMEM medium for $24 \mathrm{~h}$ and $48 \mathrm{~h}$. As shown in Fig. 2, naked pDNA release was not detected following incubation of CNs-pDNA nanoparticles up to $48 \mathrm{~h}$ in the medium. These results indicated that pDNA was very tightly associated to all nanoparticles formulation including 500:1, 300:1 and 100:1 ratios.

\subsection{Cell type-dependent cytostatic effect of CNs and CNs-pDNA}

In the first step of in vitro experiments we decided to choose working concentration of CNs-pDNA for further studies. That was

Table 1

Physical and chemical characteristics of different CNs-pDNA formulations.

\begin{tabular}{|c|c|c|c|c|}
\hline Formulation $^{\mathrm{a}}$ & Size $(n m)$ & PDI & $\zeta$ Potential $(\mathrm{mV})$ & Encapsulation efficiency (\%) \\
\hline 500:1 & $220 \pm 7.2$ & 0.581 & $+37.5 \pm 4.6$ & $94.77 \pm 4.37$ \\
\hline $300: 1$ & $206 \pm 11.8$ & 0.364 & $+33.8 \pm 1.8$ & $97.42 \pm 2.03$ \\
\hline $100: 1$ & $164 \pm 13.4$ & 0.341 & $+21.6 \pm 3.2$ & $80.95 \pm 1.03$ \\
\hline $\mathrm{CNs}^{\mathrm{b}}$ & $91.7 \pm 0.6$ & 0.214 & $+31.8 \pm 1.4$ & - \\
\hline
\end{tabular}

PDI: Polydispersity index.

a Synthesized using different CS:pDNA weight ratios of 500:1, 300:1 and 100:1 at a constant pDNA concentration of $10 \mu \mathrm{g} / \mathrm{ml}$.

b Synthesized initial chitosan nanoparticles without plasmid DNA. 


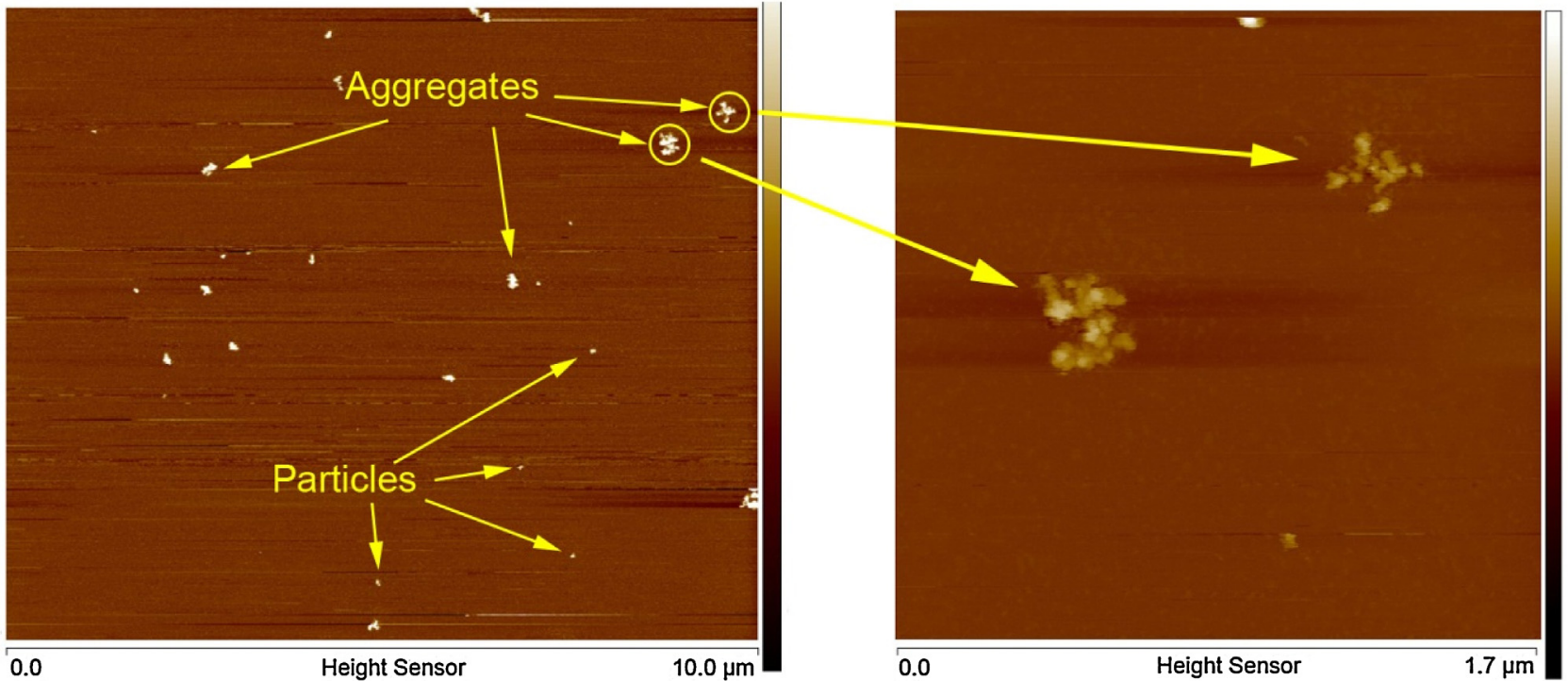

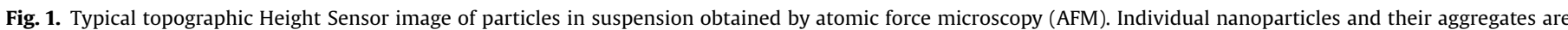
indicated by arrows. Nanoparticles were kept in DMEM medium for up to 2 days prior to AFM analysis.

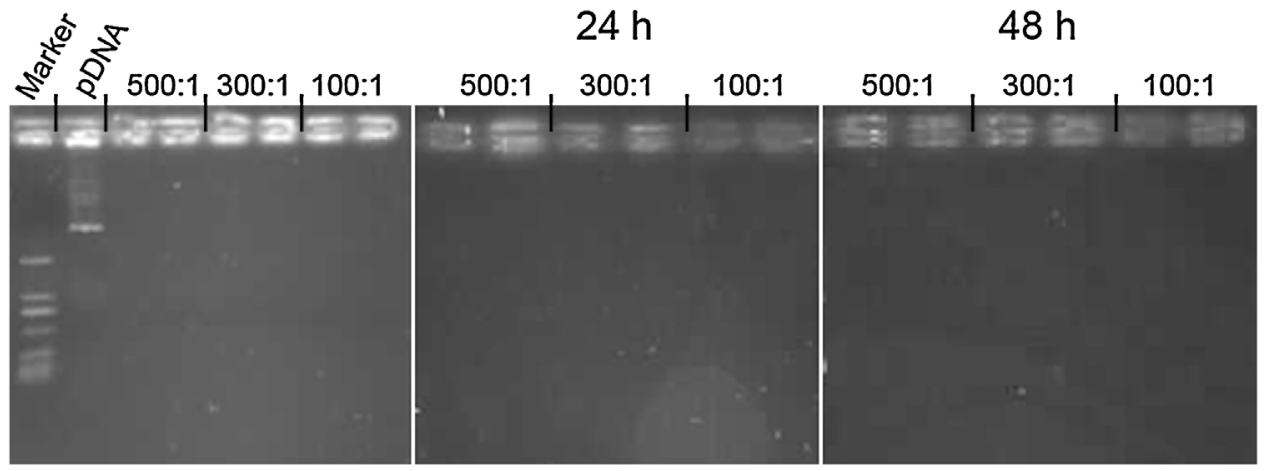

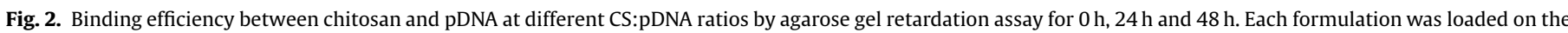
gel after it was incubated in DMEM medium at $37^{\circ} \mathrm{C}$ for $24 \mathrm{~h}$ and $48 \mathrm{~h}$

possible by the evaluation of the impact of synthesized CNs-pDNA used in the wide range of concentrations on the metabolic activity of tested cells (Fig. 3A). Performed MTT assay revealed no differences between controls and $24 \mathrm{~h}$ treated cells in the case of HeLa and MDA-MB-231 cell lines. That is in agreement with previous studies done in different cell line models, i.e. mouse hematopoietic stem cells (Omar Zaki et al., 2015), human respiratory epithelial cells (Grenha et al., 2007), human epithelial liver cells (Yang et al., 2014), mouse epithelial-like cells (Ragelle et al., 2014), mouse fibroblast colon cells (Hallaj-Nezhadi et al., 2011), human mesenchymal stem cells (Corsi et al., 2003) and human embryonic kidney cells (Corsi et al., 2003; Zhou et al., 2015). On the other hand, only a few reports have shown an inhibition in metabolic activity caused by CNs-pDNA treatment (Wimardhani et al., 2014; Yao et al., 2013). Interestingly, in our study, THP-1 monocytic metabolic activity was reduced. Treatment with plain CNs decreased their metabolic activity to the same level irrespective of used concentration (to approximately 75-82\%), while CNs-pDNA-triggered reduction was ratio- and concentration-dependent. The observed variations may be the results of methodological differences in CNs and CNs-pDNA preparation and different amounts of particular components. As seen in Fig. 3, the most pronounced effect was observed for the lowest concentrations of 500:1 CNs-pDNA (inhibition to 60\%) and the highest concentration of 300:1 and 100:1 CNs-pDNA (reduction to 54\% and $51 \%$, respectively).

As particulate carrier, CNs-pDNA containing multiple plasmids were well characterized and their transfection efficiency seems to be cell type-dependent (Corsi et al., 2003; Csaba et al., 2009; Hallaj-Nezhadi et al., 2011; Mao et al., 2001). For example, Csaba et al. (2009) showed that CNs-pDNA complexes were uptaken through endocytosis by HEK293 cells and subsequent release into the cytoplasm occurred within $14 \mathrm{~h}$, while high gene expression levels were observed two days after transfection (Csaba et al., 2009). Similarly, Hallaj-Nezhadi et al. (2011) presented 2.8 times improved transfection efficiency with the use of CNs-pDNA in comparison to naked pDNA (Hallaj-Nezhadi et al., 2011). In our study, we evaluated the efficiency of transfection with CNs-pDNA complexes (Fig. 3B). It was observed that the percentage of transfected cells after $96 \mathrm{~h}$ treatment with the formulation 500:1 (27\% HeLa, 19\% MDA-MB-231 and 29\% THP-1) was higher than 300:1 (19\% HeLa, 12\% MDA-MB-231 and 21\% THP-1) and 100:1 (21\% HeLa, 12\% MDA-MB-231 and 24\% THP-1). These results indicate that CS:pDNA has high importance for the efficacy of transfection. This is relevant with previously reported data about dependence of the surface charge ratio on the efficacy of polyplex-based gene delivery (Erbacher et al., 1998b; Lavertu et al., 2006; Romoren et al., 2003; Yue et al., 2011). Furthermore, independently from CS:pDNA 
A
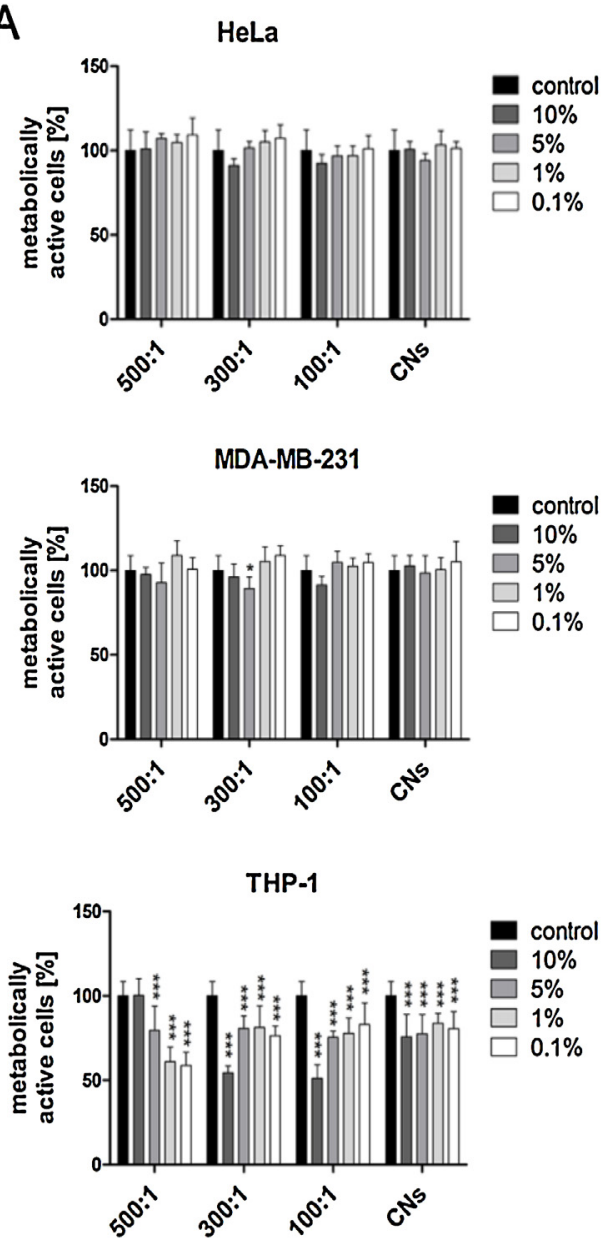

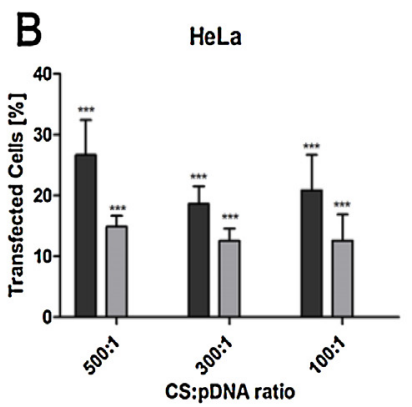

MDA-MB-231

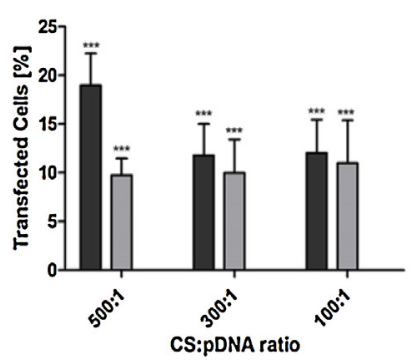

THP-1

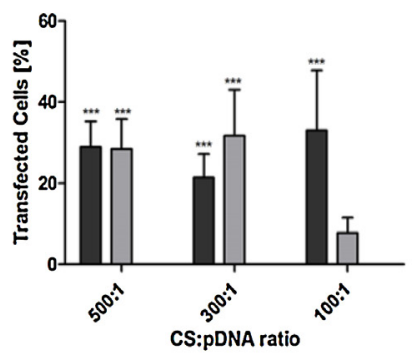

C
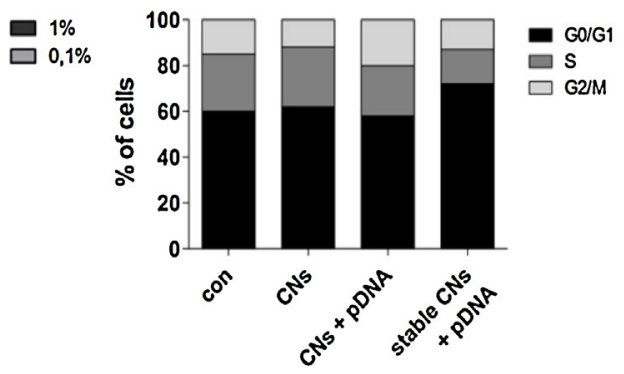

MDA-MB-231
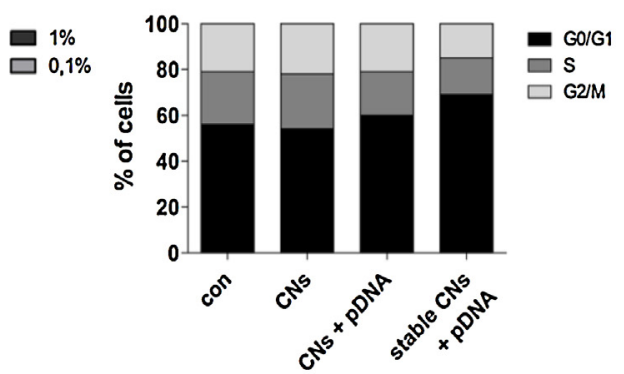

THP-1
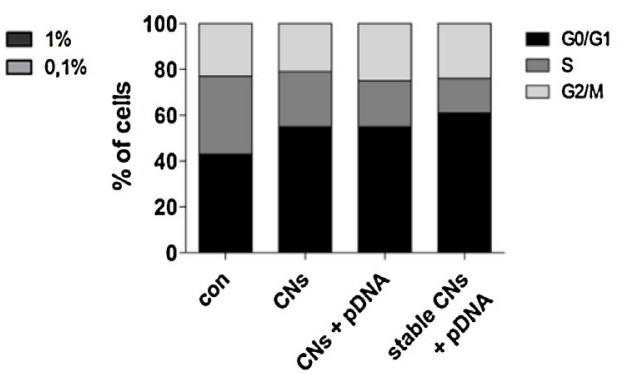

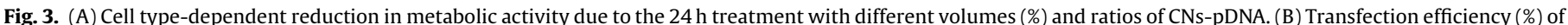

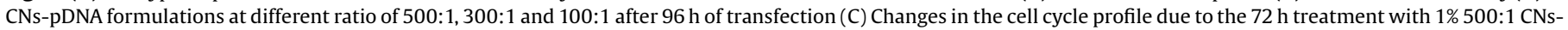
pDNA. $1 \%$ 500:1 CNs-pDNA. Bars indicate SD, $\mathrm{n}=3,{ }^{* * *} \mathrm{p}<0.001,{ }^{* *} \mathrm{p}<0.01,{ }^{*} \mathrm{p}<0.05$.

ratio, transfection efficiency also increased with time. Stable transfected cells were positive for fluorescent protein presence in almost $100 \%$ for all examined cell lines (data not shown). As reported previously (Hallaj-Nezhadi et al., 2011), short-term transfection efficiency with CNs-pDNA was lower than using Lipofectamine 2000.

The selection of working concentration for further studies was based on the interest in the identifying transfection efficiency of various formulations. Then, we wanted to define mechanism leading to the reduction of the metabolic activity of THP- 1 treated with CNs-pDNA, thus we decided to check whether that process is due to the proliferation inhibition or cell death (Fig. 3C). Therefore, we determined cell cycle profile and found these disruptions caused by $72 \mathrm{~h}$ treatment with CNs-pDNA. It was observed that the $\%$ of THP- 1 cells in the G0/G1 phase increased and in the S phase decreased at the same time. Moreover, in all examined stable transfected cells we observed G0/G1 cell cycle arrest. At the same time, the apoptotic cell death did not take place (data not shown). That process seems to be also cell type-dependent. For instance, in HaCaT, but not Ca9-22 cells, caspase-independent apoptosis was induced. However, exposure to $\mathrm{CNs}$ resulted in a significant increase in the G1 phase population (from 33\% to $51 \%$ ) indicating cell cycle arrest in Ca9-22 cells (Wimardhani et al., 2014).

\subsection{Independent of oxidative stress-induced premature senescence}

Since oxidative stress was linked with NPs-mediated toxicity (Manke et al., 2013; Mytych et al., 2015b) and affected cell cycle progression (Boonstra and Post, 2004), we decided to check whether that process also takes place in the applied conditions. Changes in generation of total ROS were monitored for evaluation of CNs-mediated oxidative stress induction in the tested cells and their reduction was observed (Fig. 4A). Moreover, antioxidant activity of CNs was coupled with their ability to suppress the production of lipid peroxidation, restore activity of endogenous antioxidant and increase total antioxidant capacity. Similar results were shown in in vitro (Wen et al., 2013) and in vivo (El-Denshary et al., 2015) models.

It is widely accepted that irreversible cell cycle arrest may lead to stress-induced premature senescence (SIPS), characterised by cytomorphological and metabolic changes (Correia-Melo and Passos, 2015). Moreover, recent findings suggest the possibility of induction of SIPS independently of ROS generation (Ziegler et al., 2015). In the present study, we noted the increase of the\% of the cells positive for the presence of SA- $\beta$-gal, which widely serves as a senescence marker (Fig. 4B). The most sensitive cell line was MDAMB-231 with the 3 times increased population of SA- $\beta$-gal positive 
A

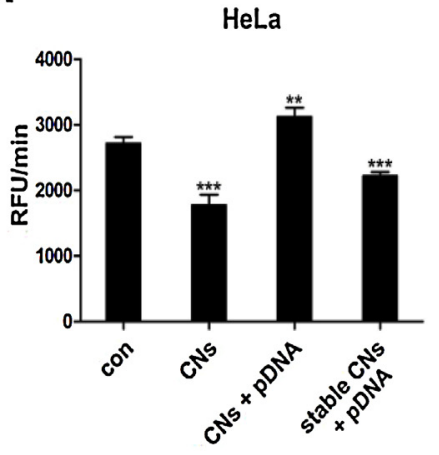

MDA-MB-231

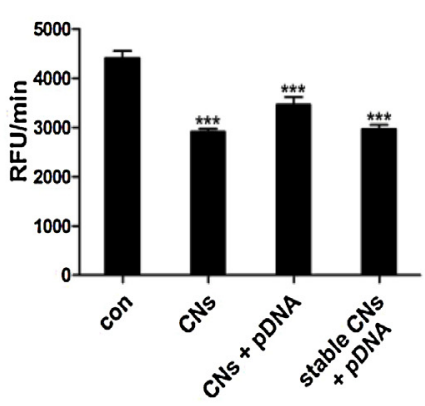

THP-1

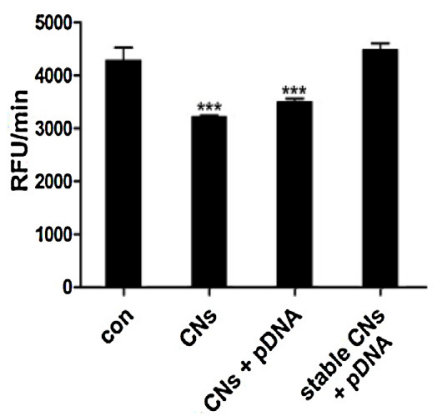

B

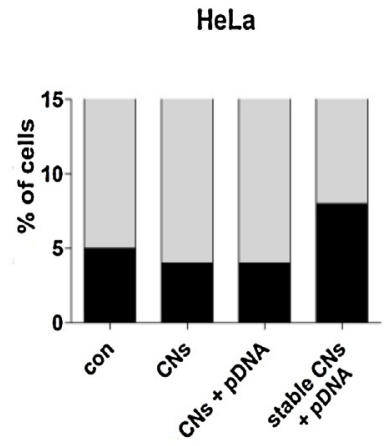

MDA-MB-231
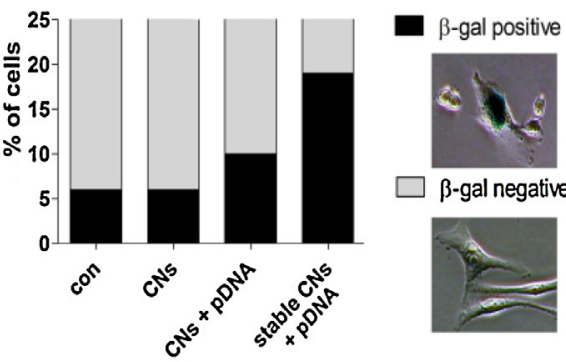

THP-1

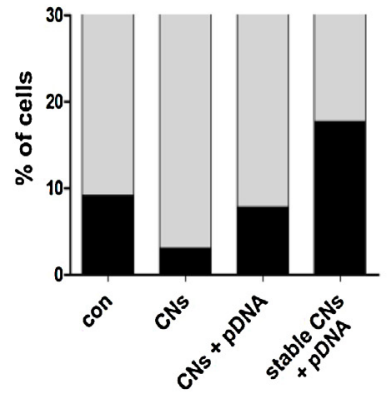

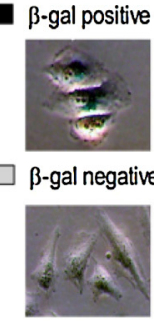

- $\beta$-gal positive

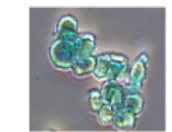

B-gal negative

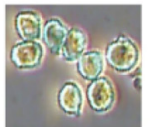

C

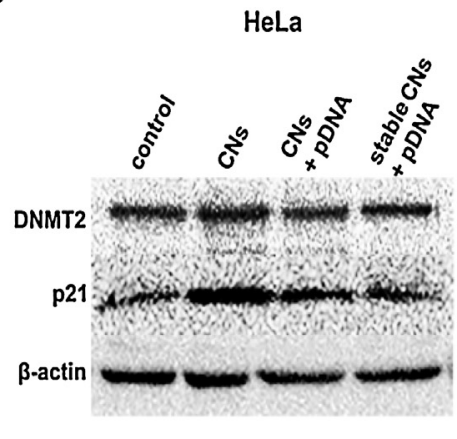

MDA-MB-231

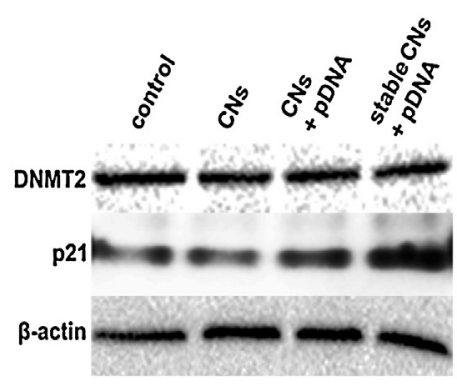

THP-1

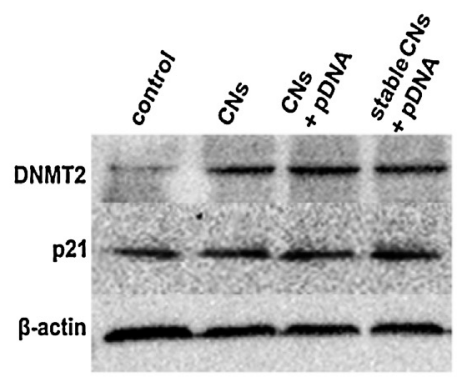

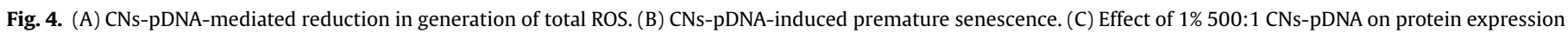
profiles. Bars indicate $\mathrm{SD}, \mathrm{n}=3,{ }^{* * *} \mathrm{p}<0.001,{ }^{* *} \mathrm{p}<0.01,{ }^{*} \mathrm{p}<0.05$; microscopic magnification of the objective lens $10 \times$.

cells, while for HeLa and THP-1 the observed change was 1.6 and 2 times higher, respectively. Furthermore, the evaluation of the level of p21 protein, another widely known marker of senescence involves as well in cell cycle arrest, was also performed (Fig. 4C). An up regulation was observed and the most pronounced effect was noted for MDA-MB-231 cell line. It was already shown that NPs can induce both, p21-dependent and p21-independent, premature senescence (Mytych et al., 2014, 2015b). Interestingly, we here report similar observation in the context of CNs-pDNA for the first time. That process may be mediated by overexpression of TGF-beta 1 which further activates p15 and p21 and leads to cell cycle arrest, resulting in cellular senescence (Gong et al., 2003; Senturk et al., 2010). The possibility that SIPS was caused by overexpression of the gene carried by CNs-pDNA and protein accumulation was excluded due to the fact that expressed fluorescent protein was characterized as non-toxic and biologically inert (Henderson and Remington, 2006). Furthermore, among many mechanisms engaged in senescence induction, also DNA and RNA methylation seems to play an important role (Machwe et al., 2000; Oh et al., 2015; So et al., 2011; Young and Smith, 2001). Besides that, DNA methyltransferase II (DNMT2), enzyme with the enigmatic role in the RNA methylation, was found to have protective role in the NPsinduced stress (Mytych et al., 2014). Therefore, we decided to check whether CNs-pDNA treatment affects the pool of DNMT2 in tested cell lines and indeed, the level of DNMT2 was elevated in THP-1 cells (Fig. 3C). Perhaps, DNMT2 upregulation in that case may result in RNA stabilization and confer stress resistance.

\section{Conclusions}

In summary, in the present study, nanoparticles based on chitosan for delivery of pKindling-red-Mito vector were successively generated by ionic gelation method at different ratio of CS: pDNA (500:1, 300:1, 100:1) with at least 80\% encapsulation efficiency and high stability. The transfection efficiency of particles was dependent on cell type and formulation. Moreover using different cell line models we showed that CNs-pDNA biocompatibility is limited and observed effects are cell-type dependent. HeLa and MDA-MB-231 cell lines, which are derived from solid tumors and exhibit adherent properties in in vitro culture, were more resistant to applied treatment than derived from blood THP-1 cells. This observation may be related to limited availability of CNs- 
pDNA to HeLa and MDA-MB-231 cell lines compared to THP-1 cells. Taking into account of the observed effects, the fact that monocytes are the first cells which are in contact with the CNs-pDNA after in vivo administration. It is crucial to understand these interactions in details before adopting proposed systems in biological and medical applications.

\section{Acknowledgments}

Gizem Bor was supported by ERASMUS PLUS. We appreciate the assistance of Dr. Malgorzata Walczak from Rzeszow University of Technology for the zeta-sizer measurements.

\section{References}

Agbulut, O., Coirault, C., Niederlander, N., Huet, A., Vicart, P., Hagege, A., Puceat, M., Menasche, P., 2006. GFP expression in muscle cells impairs actin-myosin interactions: implications for cell therapy. Nat. Methods 3, 331.

Agbulut, O., Huet, A., Niederlander, N., Puceat, M., Menasche, P., Coirault, C., 2007. Green fluorescent protein impairs actin-myosin interactions by binding to the actin-binding site of myosin. J. Biol. Chem. 282, 10465-10471.

Baens, M., Noels, H., Broeckx, V., Hagens, S., Fevery, S., Billiau, A.D., Vankelecom, H. Marynen, P., 2006. The dark side of EGFP: defective polyubiquitination. PLoS One 1 , e54.

Boonstra, J., Post, J.A., 2004. Molecular events associated with reactive oxygen species and cell cycle progression in mammalian cells. Gene 337, 1-13.

Calvo, P., Remuñán-López, C., Vila-Jato, J.L., Alonso, M.J., 1997. Novel hydrophilic chitosan-polyethylene oxide nanoparticles as protein carriers. J. Appl. Polym. Sci. 63, 125-132.

Chellat, F., Grandjean-Laquerriere, A., Le Naour, R., Fernandes, J., Yahia, L., Guenounou, M., Laurent-Maquin, D., 2005. Metalloproteinase and cytokine production by THP-1 macrophages following exposure to chitosan-DNA nanoparticles. Biomaterials 26, 961-970.

Correia-Melo, C., Passos, J.F., 2015. Mitochondria: are they causal players in cellular senescence? Biochim. Biophys. Acta 1847, 1373-1379.

Corsi, K., Chellat, F., Yahia, L., Fernandes, J.C., 2003. Mesenchymal stem cells, MG63 and HEK293 transfection using chitosan-DNA nanoparticles. Biomaterials 24 1255-1264.

Csaba, N., Koping-Hoggard, M., Alonso, M.J., 2009. Ionically crosslinked chitosan/ tripolyphosphate nanoparticles for oligonucleotide and plasmid DNA delivery Int. J. Pharm. 382, 205-214.

El-Denshary, E.S., Aljawish, A., El-Nekeety, A.A., Hassan, N.S., Saleh, R.H., Rihn, B.H., Abdel-Wahhab, M.A., 2015. Possible synergistic effect and antioxidant properties of chitosan nanoparticles and quercetin against carbon tetrachlorideInduce hepatotoxicity in rats. Soft Nanosci. Lett. 5, 36-51.

Erbacher, P., Zou, S., Bettinger, T., Steffan, A.-M., Remy, J.-S., 1998a. Chitosan-based vector/DNA complexes for gene delivery: biophysical characteristics and transfection ability. Pharm. Res. 15, 1332-1339.

Erbacher, P., Zou, S., Bettinger, T., Steffan, A.M., Remy, J.S., 1998b. Chitosan-based vector/DNA complexes for gene delivery: biophysical characteristics and transfection ability. Pharm. Res. 15, 1332-1339.

Fu, P.P., Xia, Q., Hwang, H.M., Ray, P.C., Yu, H., 2014. Mechanisms of nanotoxicity: generation of reactive oxygen species. J. Food Drug Anal. 22, 64-75.

Gan, Q., Wang, T., Cochrane, C., McCarron, P., 2005. Modulation of surface charge particle size and morphological properties of chitosan-TPP nanoparticles intended for gene delivery. Colloids Surf. B: Biointerfaces 44, 65-73.

Gong, J., Ammanamanchi, S., Ko, T.C., Brattain, M.G., 2003. Transforming growth factor beta 1 increases the stability of p21/WAF1/CIP1 protein and inhibits CDK2 kinase activity in human colon carcinoma FET cells. Cancer Res. 63, 3340-3346.

Grenha, A., Grainger, C.I., Dailey, L.A., Seijo, B., Martin, G.P., Remunan-Lopez, C., Forbes, B., 2007. Chitosan nanoparticles are compatible with respiratory epithelial cells in vitro. Eur. J. Pharm. Sci. 31, 73-84.

Hallaj-Nezhadi, S., Valizadeh, H., Dastmalchi, S., Baradaran, B., Jalali, M.B., Dobakhtti, F., Loftipour, F., 2011. Preparation of chitosan-plasmid DNA nanoparticles encoding interleukin-12 and their expression in CT-26 colon carcinoma cells. J. Pharm. Pharm. Sci. 14, 181-195.

Henderson, J.N., Remington, S.J., 2006. The kindling fluorescent protein: a transient photoswitchable marker. Physiology (Bethesda) 21, 162-170.

Huang, W.Y., Aramburu, J., Douglas, P.S., Izumo, S., 2000. Transgenic expression of green fluorescence protein can cause dilated cardiomyopathy. Nat. Med. 6, 482483.

Ibraheem, D., Elaissari, A., Fessi, H., 2014. Gene therapy and DNA delivery systems. Int. J. Pharm. 459, 70-83.

Ishii, T., Okahata, Y., Sato, T., 2001. Mechanism of cell transfection with plasmid/ chitosan complexes. Biochim. Biophys. Acta Biomembr. 1514, 51-64.

Köping-Höggård, M., Mel'nikova, Y.S., Vårum, K.M., Lindman, B., Artursson, P., 2003. Relationship between the physical shape and the efficiency of oligomeric chitosan as a gene delivery system in vitro and in vivo. J. Gene Med. 5, 130-141.
Koike, M., Yutoku, Y., Koike, A., 2013. Ku80 attentuates cytotoxicity induced by green fluorescent protein transduction independently of non-homologous end joining. FEBS Open Biol. 3, 46-50.

Lavertu, M., Méthot, S., Tran-Khanh, N., Buschmann, M.D., 2006. High efficiency gene transfer using chitosan/DNA nanoparticles with specific combinations of molecular weight and degree of deacetylation. Biomaterials 27, 4815-4824.

Liu, H.S., Jan, M.S., Chou, C.K., Chen, P.H., Ke, N.J., 1999. Is green fluorescent protein toxic to the living cells? Biochem. Biophys. Res. Commun. 260, 712-717.

Machwe, A., Orren, D.K., Bohr, V.A., 2000. Accelerated methylation of ribosomal RNA genes during the cellular senescence of Werner syndrome fibroblasts. FASEB J. $14,1715-1724$.

Manke, A., Wang, L., Rojanasakul, Y., 2013. Mechanisms of nanoparticle-induced oxidative stress and toxicity. Biomed. Res. Int. 2013, 942916.

Mao, H.Q., Roy, K., Troung-Le, V.L., Janes, K.A., Lin, K.Y., Wang, Y., August, J.T., Leong, K.W., 2001. Chitosan-DNA nanoparticles as gene carriers: synthesis, characterization and transfection efficiency. J. Control Release 70, 399-421.

Matsumoto, Y., Itaka, K., Yamasoba, T., Kataoka, K., 2009. Intranuclear fluorescence resonance energy transfer analysis of plasmid DNA decondensation from nonviral gene carriers. J. Gene Med. 11, 615-623.

Mytych, J., Lewinska, A., Bielak-Zmijewska, A., Grabowska, W., Zebrowski, J., Wnuk, M., 2014. Nanodiamond-mediated impairment of nucleolar activity is accompanied by oxidative stress and DNMT2 upregulation in human cervical carcinoma cells. Chem. Biol. Interact 220, 51-63.

Mytych, J., Lewinska, A., Zebrowski, J., Wnuk, M., 2015a. Nanodiamond-induced increase in ROS and RNS levels activates NF- $\kappa$ B and augments thiol pools in human hepatocytes. Diamond Relat. Mater. 55, 95-101.

Mytych, J., Pacyk, K., Pepek, M., Zebrowski, J., Lewinska, A., Wnuk, M., 2015b. Nanoparticle-mediated decrease of lamin B1 pools promotes a TRF proteinbased adaptive response in cultured cells. Biomaterials 53, 107-116.

Oh, Y.S., Jeong, S.G., Cho, G.W., 2015. Anti-senescence effects of DNA methyltransferase inhibitor RG108 in human bone marrow mesenchymal stromal cells. Biotechnol. Appl. Biochem. 62, 583-590.

Omar Zaki, S.S., Ibrahim, M.I., Katas, H., 2015. Particle size affects concentrationdependent cytotoxicity of chitosan nanoparticles towards mouse hematopoietic stem cells. J. Nanotechnol. 2015, 1-5.

Perez-Martinez, F.C., Guerra, J., Posadas, I., Cena, V., 2011. Barriers to non-viral vector-mediated gene delivery in the nervous system. Pharm. Res. 28, $1843-$ 1858.

Ragelle, H., Riva, R., Vandermeulen, G., Naeye, B., Pourcelle, V., Le Duff, C.S., D'Haese, C., Nysten, B., Braeckmans, K., De Smedt, S.C., Jérôme, C., Préat, V., 2014. Chitosan nanoparticles for siRNA delivery: optimizing formulation to increase stability and efficiency. J. Control. Release 176, 54-63.

Romoren, K., Pedersen, S., Smistad, G., Evensen, O., Thu, B.J., 2003. The influence of formulation variables on in vitro transfection efficiency and physicochemical properties of chitosan-based polyplexes. Int. J. Pharm. 261, 115-127.

Rossert, J., Yue, S., Smirnakis, K., Mytych, D.T., Johnson, L., Kouchakji, E., Casadevall, N., 2014. Risk of pure red cell aplasia in patients with hepatitis $C$ receiving antiviral therapy and an erythropoiesis-stimulating agent. Clin. Gastroenterol. Hepatol. 12, 341-345.

Senturk, S., Mumcuoglu, M., Gursoy-Yuzugullu, O., Cingoz, B., Akcali, K.C., Ozturk, M., 2010. Transforming growth factor-beta induces senescence in hepatocellular carcinoma cells and inhibits tumor growth. Hepatology 52, 966974.

So, A.Y., Jung, J.W., Lee, S., Kim, H.S., Kang, K.S., 2011. DNA methyltransferase controls stem cell aging by regulating BMI1 and EZH2 through microRNAs. PLoS One 6, e19503.

Sudheesh Kumar, P.T., Raj, N.M., Praveen, G., Chennazhi, K.P., Nair, S.V., Jayakumar, R., 2013. In vitro and in vivo evaluation of microporous chitosan hydrogel/ nanofibrin composite bandage for skin tissue regeneration. Tissue Eng. A 19, 380-392.

Wen, Z.S., Liu, L.J., Qu, Y.L., Ouyang, X.K., Yang, L.Y., Xu, Z.R., 2013. Chitosan nanoparticles attenuate hydrogen peroxide-induced stress injury in mouse macrophage RAW264.7 cells. Mar. Drugs 11, 3582-3600.

Wimardhani, Y.S., Suniarti, D.F., Freisleben, H.J., Wanandi, S.I., Siregar, N.C., Ikeda, M. A., 2014. Chitosan exerts anticancer activity through induction of apoptosis and cell cycle arrest in oral cancer cells. J. Oral. Sci. 56, 119-126.

Yang, M.H., Yuan, S.S., Huang, Y.F., Lin, P.C., Lu, C.Y., Chung, T.W., Tyan, Y.C., 2014. A proteomic view to characterize the effect of chitosan nanoparticle to hepatic cells: is chitosan nanoparticle an enhancer of PI3 K/AKT1/mTOR pathway? Biomed. Res. Int. 2014, 789591.

Yao, Q., Liu, W., Gou, X.J., Guo, X.Q., Yan, J., Song, Q., Chen, F.Z., Zhao, Q., Chen, C., Chen, T., 2013. Preparation, characterization, and cytotoxicity of various chitosan nanoparticles. J. Nanomater. 2013, 1-6.

Young, J.I., Smith, J.R., 2001. DNA methyltransferase inhibition in normal human fibroblasts induces a p21-dependent cell cycle withdrawal. J. Biol. Chem. 276, 19610-19616.

Yue, Z.-G., Wei, W., Lv, P.-P., Yue, H., Wang, L.-Y., Su, Z.-G., Ma, G.-H., 2011. Surface charge affects cellular uptake and intracellular trafficking of chitosan-based nanoparticles. Biomacromolecules 12, 2440-2446.

Zhou, Y., Li, J., Lu, F., Deng, J., Zhang, J., Fang, P., Peng, X., Zhou, S.F., 2015. A study on the hemocompatibility of dendronized chitosan derivatives in red blood cells. Drug Des. Dev. Ther. 9, 2635-2645.

Ziegler, D.V., Wiley, C.D., Velarde, M.C., 2015. Mitochondrial effectors of cellular senescence: beyond the free radical theory of aging. Aging Cell 14,1-7. 